\title{
Microstructural Evolution and Wear Behavior of HVOF Spraying WC/Co Coatings Produced by Laser Cladding
}

\begin{abstract}
G. LIAN AND M. JEAN*
Fujian University of Technology, School of Mechanical and Automotive Engineering, 350118 Fuzhou, China

This study reports that laser-treated HVOF-spray coated surfaces of WC/Co composite were fabricated on 45 carbon substrates using laser treatment technology. The hardfacing coatings were applied by combining two different techniques of HVOF spraying and laser irradiation. Wear behavior of the coatings was systematically investigated, and microstructural evolution of the laser melted HVOF-sprayed coatings was characterized and compared with that of HVOF-sprayed coatings. Microstructural observation shows that both coatings exhibit similar phases, but there are differences in the formation of tungsten carbide, micro-hardness distribution, closely packed structures and wear behaviors of the coatings. Coatings with evenly distributed WC ceramic phases and a better bonding mechanism to the substrate alloy were obtained by laser-based HVOF spraying treatment. The results of this study indicate that the wear behaviors of the HVOF-sprayed WC/Co composite coatings prepared by laser irradiation are much better than those of the plain HVOF-sprayed coating. The wear volume loss of HVOF-sprayed WC/Co composite coating prepared by laser melting treatment is the lowest, only $50 \%$ of that of the HVOF-sprayed coating, thereby providing better wear resistant properties. Overall, the increase in wear resistance was attributed to the formation of dendritic-tungsten carbide, high micro-hardness distribution and to closely packed structures of the coatings.
\end{abstract}

DOI: 10.12693/APhysPolA.134.93

PACS/topics: WC/Co, laser melting, high velocity oxygen fuel, mechanical properties, microstructure

\section{Introduction}

The rapid development of hard coatings in recent years is largely due to the availability of advanced joining techniques that can provide previously unachievable properties [1-3]. These new properties have attracted substantial attention from numerous researchers and engineers and have various applications, in polymer materials, biomedical applications, electronic parts, automobiles, and other [4-6].

Such current technologies as electroplating, electroless plating, hot-dip galvanizing, wire arcs, flames, brazing, or weld overlays have been developed to provide protection against friction and corrosion by isolating the material from chemical and physical interaction with its environment. However due to such difficulties as softness, low wear resistance, difficulty with welding and structural defects, these technologies may provide insufficient protection for certain applications requiring high hardness, wear resistance, or thermal protection [7-10].

Because it resolves many of these problems, the high velocity oxy-fuel (HVOF) spraying technique has a considerable potential for applications in various sectors of surface engineering, especially for protection against abrasion and adhesion, as well as against corrosion [11-14].

Recently there have been numerous publications describing metal matrix composite coatings, since they have proved effective in enhancing the corrosion and wear re-

*corresponding author; e-mail: mdjeam@foxmail.com sistance of substrate materials. A series of ceramic materials have been widely introduced into metal matrix composite coatings, such as $\mathrm{WC}, \mathrm{VC}, \mathrm{SiC}$, or $\mathrm{TiC}$, which are deposited to protect materials from severe abrasion by reducing wear and friction [15-18].

Tungsten carbide in a cobalt binder has attracted increasing interest in the field of wear of surface engineering, and it has been widely used in a number of engineering applications such as cutting tools and dies, drill bits for mining, and wear-resistant nozzles. These applications have been the subject of much study and many reports on the development of protective coatings by the application of HVOF-sprayed coatings to improve the tribological properties of materials.

However, the application of HVOF sprayed coatings has such disadvantages, as porosity and partial melting, and the fact that mechanical bonding is severely restricted under specific wear environments [19-21]. In order to further improve the properties of these coatings, we propose a highly effective method that combines HVOF spraying along with laser cladding to improve the surface properties of substrates for protection against wear and corrosion.

Laser cladding has received significant attention in recent years. It offers many advantages over conventional coating processes due to the high accuracy and low thermal effect of the base material [22]. Laser cladding processes provide solutions for HVOF coating problems due to their remarkable and technologically attractive properties that improve the surface properties of many kinds of metals processed by HVOF spraying $[7,8]$. The specific properties include high hardness, low density, high melting temperature, high modulus and good resistance to wear and corrosion. 
Laser cladding also provides a promising technique for controlling and solving problems like high percentage of porosity, or weak interconnection between the solidified splats and an inhomogeneous coating structure in HVOF sprayed coatings. Several researchers have worked in this field [23, 24], but there are very few studies reporting on the laser melting of $\mathrm{HVOF}$ sprayed WC/Co coatings.

For this study, HVOF WC/Co coatings for 45 carbon steel were produced using $\mathrm{Yb}$ :YAG laser cladding melting. Microstructural evolution, phase constitution, microhardness and wear resistance of the WC/Co composite coatings and wear properties of the coatings were then explored. Particular attention was given to comparative study of the microstructure and wear resistance of the WC/Co composite coatings produced before and after laser melting.

\section{Materials and preparation}

\subsection{Materials}

In the present study, $\mathrm{WC} / \mathrm{Co}$ powders (W Bal., Co 7.8 wt.\%, C 5.3 wt.\%, Fe 0.06 wt.\%) were used as feedstock powders for sample preparation for a part of this series of experiments. The sprayed powder was examined under a SEM, as shown in Fig. 1. It was found that the particle sizes ranged from 20 to $40 \mu \mathrm{m}$. It was observed that most of the particles were nearly spherical in shape and some had small attached satellites. The satellite particles were typically $4-15 \mu \mathrm{m}$ in size.

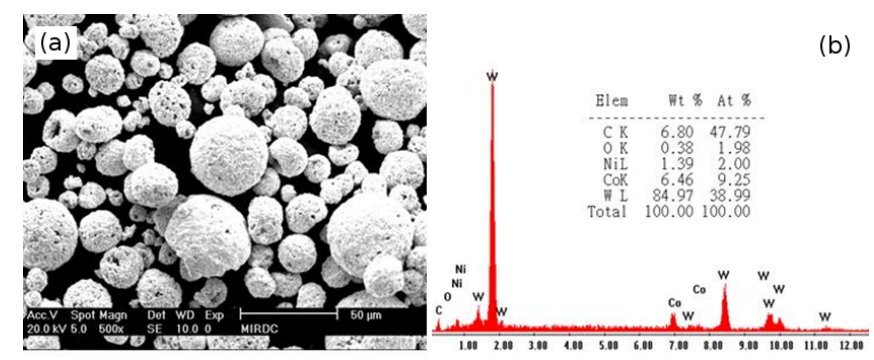

Fig. 1. (a) SEM image of the as-received WC-8 wt.\% Co powder, (b) EDS analysis of the WC-Co powder.

The substrate samples, with dimensions of $40 \times 40 \times$ $10 \mathrm{~mm}^{3}$, were of ASTM mild steel, and were blasted with $\mathrm{Al}_{2} \mathrm{O}_{3}$ grit to achieve surface roughness ( $\mathrm{Ra}$ ) between 4 and $5 \mu \mathrm{m}$, and than they were ultrasonically cleaned with acetone.

\subsection{Coating deposition}

A process for laser-based HVOF spraying was developed in the present study for improving the carbide coatings. Figure 2 shows a scheme of the procedure for the laser-based HVOF-spraying processes, and the surface morphology of the coatings before and after the laser melting.

Tested coatings were based on HVOF spraying, made using Sulzer Metco F4M system. Laser irradiation of the

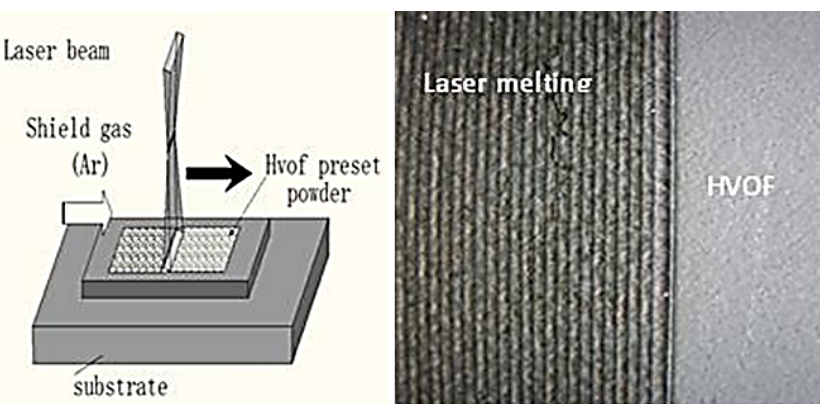

Fig. 2. (a) Schematic diagram of the laser-based processing of the HVOF-sprayed coatings, (b) surface morphology of the coatings (HVOF spraying) before and after laser melting with Nd:YAG laser.

coatings was carried out using an Nd:YAG laser. Before laser melting, the substrate was covered by HVOF spraying, after which the coating layers were were melted by laser irradiation.

Thus, all samples were first sprayed using a Sulzer Metco Diamond Jet Hybrid DJH 2700 high-velocity oxyfuel spraying equipment. WC-Co coatings, with an interlayer of NiCrAlY, were deposited on the blasted surface of mild steel. The spraying parameters used to produce WC/Co coatings in this study are shown in Table I.

TABLE I

Parameters and conditions used during high velocity oxygen fuel spraying processes.

\begin{tabular}{l|c}
\hline \hline Symbol & $\mathrm{H} 1$ \\
Coating type & $\mathrm{NiCr} / \mathrm{WC}-\mathrm{Co}$ \\
$\mathrm{CH} 4$ flow $[1 / \mathrm{min}]$ & 40 \\
$\mathrm{O}_{2}$ flow $[\mathrm{l} / \mathrm{min}]$ & 40 \\
Spraying distance $[\mathrm{cm}]$ & 20 \\
Travel speed $[\mathrm{cm} / \mathrm{min}]$ & 31 \\
Powder feed rate $[\mathrm{g} / \mathrm{min}]$ & 40 \\
Carrier gas flow $[\mathrm{l} / \mathrm{min}]$ & 29 \\
\hline
\end{tabular}

Subsequently, laser melting of coatings based on HVOF spraying was carried out to fabricate the final coating. As shown in Table II, the control parameters used during the process of laser melting were: laser power of 800 and $1000 \mathrm{~W}$; pulse frequency of 50 and $60 \mathrm{~Hz}$; scan speed of 3 and $5 \mathrm{~mm} / \mathrm{s}$; pulse duration of 1 and $2 \mathrm{~mm}$, focal distance of $2 \mathrm{~mm}$ below and $2 \mathrm{~mm}$ above the focus plane and air pressure of 1 and $2 \mathrm{kgf} / \mathrm{mm}^{2}$. Although some reports on the application of laser cladding to $\mathrm{WC} / \mathrm{Co}$ alloy coatings have been published $[4,5]$, further study is needed to determine how to produce an excellent WC/Co composite coating by choosing the proper laser parameters.

\subsection{Characterization}

The phase composition of the coatings and wear marks were studied by X-ray diffraction (XRD) using a SIEMENS D8A diffractometer with $\mathrm{Cu}-\mathrm{K}_{\alpha}$ radiation operated at $40 \mathrm{kV}$ and $25 \mathrm{~mA}$. The samples were scanned 
TABLE II

Parameters controlling laser irradiation and their values.

\begin{tabular}{l|c|c}
\hline \hline Symbol & L1 & L2 \\
Laser power $[\mathrm{W}]$ & 800 & 1000 \\
Pulse frequency $[\mathrm{Hz}]$ & 40 & 60 \\
Pulse duration $[\mathrm{mm}]$ & 1 & 2 \\
Focal distance $[\mathrm{mm}]$ & 2 & -2 \\
Travel speed $[\mathrm{mm} / \mathrm{s}]$ & 3 & 5 \\
Air pressure $\left[\mathrm{kgf} / \mathrm{mm}^{2}\right]$ & 1 & 2 \\
\hline
\end{tabular}

from 200 to 1000 with scan step of 0.050 . Microstructures of the coatings and of the worn surfaces and debris after sliding wear tests were examined using a JEOL JSM6700 SEM equipped with energy-dispersive X-ray (EDX) microanalysis. For elemental analysis the EDS was used and profile quantitative elemental analysis was carried out. Micro-hardness of the coatings was assessed using Vicker micro-hardness tester under the load of $300 \mathrm{gf}$ and for dwell time of $15 \mathrm{~s}$. An average of ten readings is reported.

\subsection{Wear test}

Coated specimens were tested using a tribometer with a computer-controlled pin-on-disc configuration. A tungsten carbide ball counterpart with a diameter of $12 \mathrm{~mm}$ was used. The loading for wear tests was $10 \mathrm{~N}$, sliding diameter was $20 \mathrm{~mm}$ and the rotation speed was $286 \mathrm{rpm}$. The sliding speed was $30 \mathrm{~cm} / \mathrm{s}$ and the sliding distance of tests was 1000 meters. The worn surface and the microstructures of the coatings were analyzed using scanning electron microscopy.

The elemental analysis of the surfaces of wear marks was investigated using EDS. The wear tracks were further examined using X-ray diffraction patterns. Wear volume loss was determined by a dedicated 3D scanning system (TalyScan 150), which was used to measure the morphology and to convert this data to the wear volume of the wear tracks.

\section{Results and discussion}

\subsection{Metallography of HVOF coating}

Figure 3 shows the surface morphology, cross-section etched image, magnified surface microstructure and EDS of HVOF coating made of WC-Co powder. As seen in Fig. 3a, the surface morphology, which is relatively smooth, shows partially melted lamellae grains and microstructural defects, such as a micro-porosity, cracking or unmelted structures in the WC-Co coatings.

Figure $3 \mathrm{~b}$ shows the cross sectional microstructures with interlayered $\mathrm{NiCr}$, imaged by a $5 \% \mathrm{NaCl}$ etching. These microstructures were very similar for the all trials, being incompletely melted with a melt depth of about $150 \mu \mathrm{m}$ and splat thickness of about $5 \mu \mathrm{m}$. A typical mechanical interlocking bonding mechanism at the coating/substrate interface is observed with a gap of $2-3 \mu \mathrm{m}$ between the coating and the substrate. The cermet particles, therefore, cannot spread and flatten extensively, resulting in small defects and pores remaining within the substrate/coatings. Clearly, the main location of failure is at the coating/substrate interface.

As shown in high magnification images of the top surface of the coatings in Fig. 3c, the impinging droplets of the $\mathrm{WC} / \mathrm{Co}$ particles are intensively flattened during deposition. The WC-Co coating displays a clearly recognizable splat structure. It flattens extensively while melted, with thin lamellae grains and microstructural defects, such as micro-porosities, long cracks and unmelted structures. The presence of $\mathrm{C}, \mathrm{W}, \mathrm{Co}, \mathrm{Ni}$ and $\mathrm{O}$ is clearly seen from the EDS pattern shown in Fig. 3d. The energy dispersive spectroscopy (EDS) analysis of the WCCo powder indicates $39.06 \% \mathrm{~W}, 17.92 \%$ Co, $17.81 \% \mathrm{C}$, $1.85 \% \mathrm{Ni}$ and $23.36 \%$ of $\mathrm{O}$ elements.
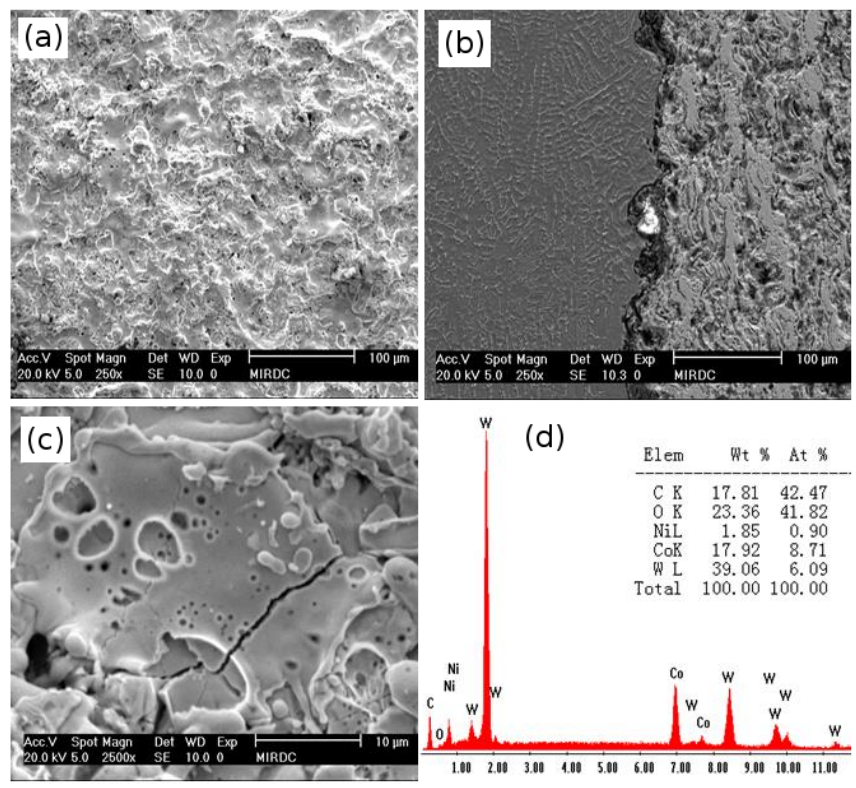

Fig. 3. Surface morphology, cross-sectional etched image, magnified surface microstructure and EDX of HVOF coatings.

\subsection{Metallography of laser melted HVOF spraying coating}

Figure 4 shows the surface morphology, cross-sectional microstructure and EDS spectra of the HVOF coatings after laser melting treatment. As shown in Fig. 4a, the laser-processed layers of the $\mathrm{HVOF}$ coatings are fully melted structures. The WC/Co coating displays a clearly recognizable dense structure.

In Fig. 4b, the cross-sectional microstructures are completely melted with $\mathrm{NiCr}$ interlayered to the substrate. The microstructures are characterized by presence of melted WC/Co deposits with a strong metallurgical bonding to the substrate due to laser-melting of HOVF-sprayed coatings, leading to the improved bonding strength of the coating. 

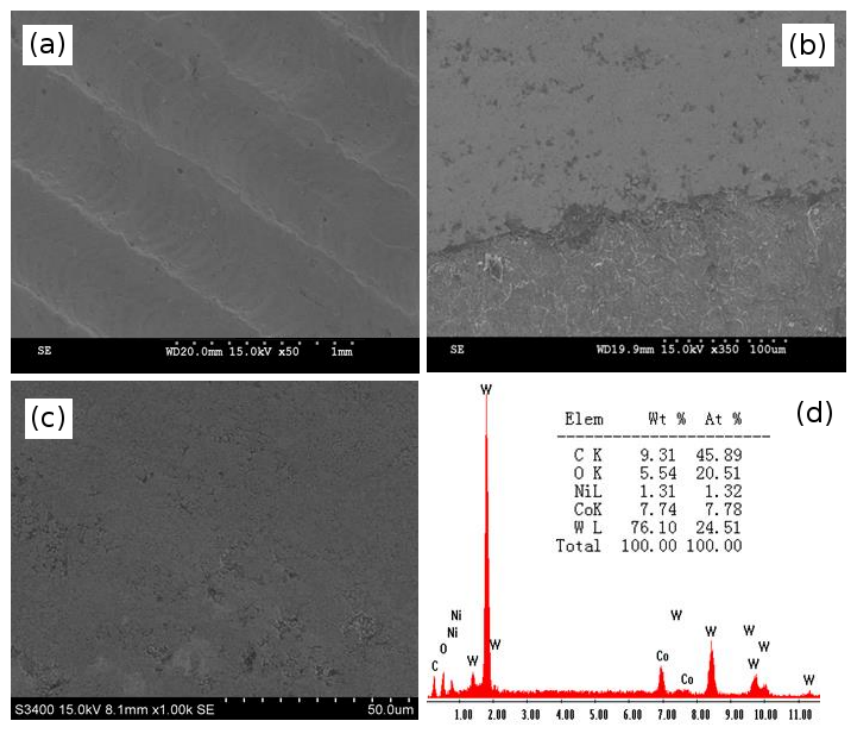

Fig. 4. Surface morphology, cross-sectional microstructure and EDX spectra of the HVOF coatings after laser melting treatment.

For further study, the enlarged SEM images of Fig. 4a are shown in Fig. 4c. These coatings with less porosity, fewer defects and more homogeneous structure exhibit dense deposits. In addition, the content of $\mathrm{W}$ element of more than $76 \%$ in Fig. $4 \mathrm{~d}$ is remarkably different, from that in Fig. 3d, where the EDS spectra of the HVOF spraying show less than $40 \%$ of $\mathrm{W}$. On the other hand, the results of EDS analysis in Fig. 1b show that levels of $\mathrm{W}$ elements are similar and that undissolved $\mathrm{WC}$ particles are detected. Thus, the wear resistance of the $\mathrm{WC} / \mathrm{Co}$ composite coating is correlated to the content and distribution of undissolved WC particles and the microstructural evolution of the composite coatings.

For this study, two trials were conducted. At a lower power of $800 \mathrm{~W}$, the microstructural evolution shows looser features with many pores and partially melted $\mathrm{WC} /$ Co particles. With the higher power of $1000 \mathrm{~W}, \mathrm{WC}$ particles are distributed unevenly and are fully melted. Therefore, to obtain better wear resistance after laser melting of $\mathrm{WC} / \mathrm{Co}$ composite coating, moderate conditions are necessary. In the present study, the optimized laser power was found to be $1.0 \mathrm{~kW}$, for the L2 sample.

\subsection{SEM observation of wear properties}

SEM images of wear behavior of the WC/Co coatings in Fig. 5 display the various wear surfaces after sliding of $10 \mathrm{~N}$ load for a sliding distance of 1000 meters. The laser-based HVOF WC-8\% Co coatings have significantly different attrition surface micrographs than the conventional HVOF-based sprayed coatings. Figure 5 shows a representative SEM micrograph of worn surface of the deposited coatings along with the typical chemical composition analyzed by EDS.

Figure $5 \mathrm{a}$ shows some adhesive wear damage to the HVOF WC-Co coating subjected to sliding wear. This
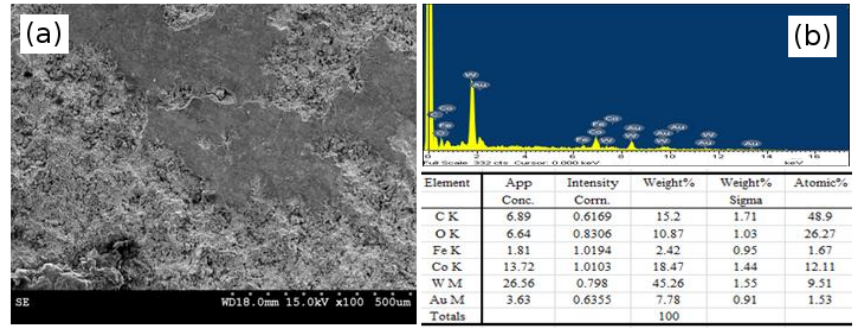

Fig. 5. SEM micrographs of worn surfaces and results of EDS analysis for $\mathrm{H} 1$ coatings deposited using $\mathrm{HVOF}$ process.

is followed by a gradual removal of WC and Co particles and less plastic deformation on the surface with a wear track of about $3 \mathrm{~mm}$ in width. The wear track exhibits a smooth deformed zone but occurs in discrete areas and material loss is not uniform across the wear track. This indicates that the deformable areas, with a lower roughness have higher wear resistance than other areas.

According to the EDS analysis shown in Fig. 5b, the transferred debris contain large amounts of W, C, Co and $\mathrm{O}$, but a small amount of Fe. Clearly, the iron debris peeled from the hardened counterpart were carried into the wear track. Furthermore, the results of EDS analysis shown in Fig. 5b should be compared with those of the asreceived powders. The contents of $\mathrm{W}, \mathrm{O}_{2}$ and $\mathrm{C}$ element of HVOF coatings have changed from 84.97 to $45.26 \%$, from 0.38 to $10.87 \%$ and from 6.8 to $15.2 \%$, respectively in the $\mathrm{H} 1$ sample. In addition, peaks of $\mathrm{W}_{2} \mathrm{C}, \mathrm{W}$ and $\mathrm{Co}$ phases in the XRD spectra also appear. This implies that the $\mathrm{H} 1$ sample was not completely melted, and several portions of $\mathrm{WC} / \mathrm{Co}$ particles have decomposed during their transformation to softer $\mathrm{W}_{2} \mathrm{C}, \mathrm{W}$ and graphite $\mathrm{C}$.

Figure 6 shows SEM micrographs of worn surfaces and results of EDS analysis for sample L1, subjected to sliding wear of the coatings deposited by laser melting. Smooth grooves about $6 \mathrm{~mm}$ wide with deep pits within the wear track appear on the worn surface, which indicates abrasive wear damage formed by the wear from 1000 meters of sliding.
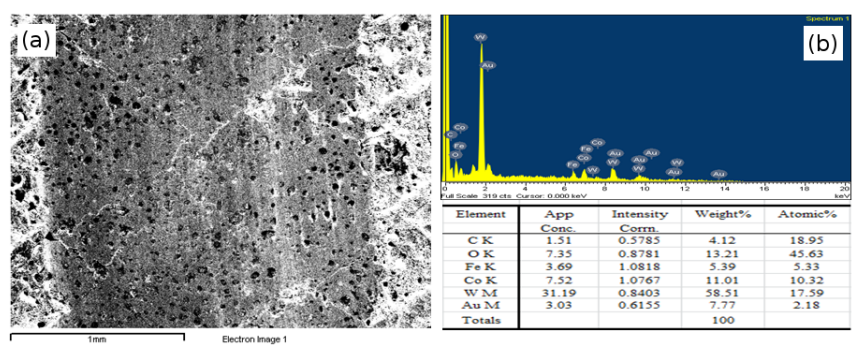

Fig. 6. SEM micrographs of worn surface and results of EDS analysis of sample produced using laser power of $800 \mathrm{~W}$ and subjected to sliding wear of the coatings deposited by laser melting. 
The clear ploughing grooves indicate that the main wear mechanism in the case of the L1 sample was abrasive wear, and there is no sign of fatigue spalling or plastic deformation on the worn surface. The surface is characterized by furrows with deep and wide continuous tracks following abrasion, and limited occurrence of surface splat delamination by HVOF.

Due to their larger melted surface, as clearly demonstrated by micro indentation tests in Fig. 6a, the preexisting pores in these areas cause the binder phase to become brittle and hard, and therefore less able to reduce the overall wear loss of the L1 sample produced by laser melting. This continues until some wear scars near the zone of the porosities become unsupported and are pulled off the surface. This explains why wear mechanisms of HVOF coatings are different from those of laser-based HVOF samples.

The results of EDS analysis shown in Fig. $6 \mathrm{~b}$ should be compared with those of the as-received powders. The contents of $\mathrm{W}, \mathrm{O}_{2}$ and $\mathrm{C}$ elements in the $\mathrm{L} 1$ sample prepared by laser melting have changed from 84.97 to $58.51 \%$, from 0.38 to to $13.21 \%$ and from 6.8 to $4.12 \%$, respectively. Several portions of $\mathrm{WC} / \mathrm{Co}$ particles, that decomposed during transformation to softer $\mathrm{W}_{2} \mathrm{C}, \mathrm{W}$ and graphite $\mathrm{C}$, were not fully remelted after laser melting, and are therefore more porous. This treatment could result in brittle and hard structures that are more susceptible to wear, probably due to improper control of the treatment of $\mathrm{WC} / \mathrm{Co}$ by laser irradiation.

SEM images of the worn surfaces of the L2 coating together with the results of EDS microanalysis in Fig. 7 indicate several levels of fatigue spalling that only occurred near the crack area, as well as some tiny grooves in the deformed area of the wear mark, which are consistent with the wear results.
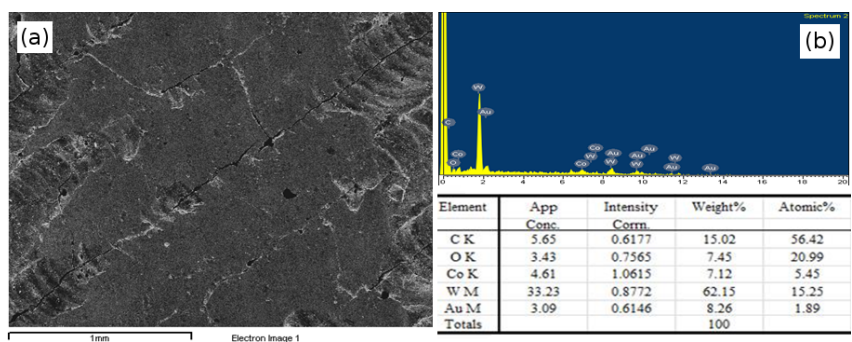

Fig. 7. Representative SEM micrograph of wear-track morphology along with the results of EDS analysis after sliding wear tests of sample produced using laser power of $1000 \mathrm{~W}$ for the deposition by laser melting.

As shown in Fig. 7a, the worn surface of the L2 sample shows evidence of plastic deformation, with some pits within the wear track being about $2 \mathrm{~mm}$ in width. The wear mechanism in the case of the L2 sample is dominated by adhesive wear of $\mathrm{WC}$ and Co particles from the coating, which have been plastically deformed and were uniformly distributed in the tracks after adhesion.
This results in the formation of a smooth contact surface, which helps to decrease the ploughing effects within the wear track, and thereby to improve the wear resistance of the coating.

According to the EDS analysis shown in Fig. 7, the transferred debris contain large amounts of $\mathrm{W}$ and $\mathrm{C}$, and small amounts of $\mathrm{O}$ and Co. The undissolved WC particles in the coatings are beneficial for high wear resistance. Furthermore, the EDS analysis shown in Fig. 7b indicates that the contents of $\mathrm{W}, \mathrm{O}_{2}$ and $\mathrm{C}$ elements of the L2 sample produced by laser irradiation have changed from 84.97 to $62.15 \%$, from 0.38 to $7.45 \%$, and from 6.8 to $15.02 \%$, in comparison with the as-received powder, respectively, as was confirmed by XRD analysis.

In addition, peaks from $\mathrm{W}_{2} \mathrm{C}$ phases in the XRD spectra are slightly visible. These results are consistent with the XRD patterns, implying that the L2 sample is completely melted, and only a small amount of $\mathrm{W}_{2} \mathrm{C}$ can be seen in Fig. 7b. In other words, the L2 sample has suffered a lower decarburization than the H1 sample, indicating that the structure of the L2 sample is homogenous and therefore the pre-existing cracks do not propagate after the wear testing.

This demonstrates that the L2 sample has an excellent wear resistance, better than that of the $\mathrm{H} 1$ sample. Moreover, the wear volume losses of the L2 sample were significantly smaller than those of the L1 sample. This can be attributed to the structure of the L2 sample becoming denser along with the obvious strengthening effects of carbides (WC) at the contact zone. Therefore, sliding wear resistance was enhanced further, whereas the opposite can be observed for the L1 sample due to the formation of soft oxide particles formed by $\mathrm{W}_{2} \mathrm{C}$, and numerous porosities in the contact surface. This corresponds to the better wear resistance of the L2 sample compared to those of both the L1 and the H1 samples.

Figure 8 shows the XRD diagrams of the coatings before (H1) and after (L2) the laser melting. In both cases phase compositions with $\mathrm{WC}$ and $\mathrm{W}_{2} \mathrm{C}$ phases were found to be almost the same, but their intensity varied. Furthermore, the differences between diffraction peaks in the XRD spectra of the coatings, corresponding to WC and $\mathrm{W}_{2} \mathrm{C}$ carbide phases, are also noticeable. The L2 sample exhibits slightly smaller amount of $\mathrm{W}_{2} \mathrm{C}$ phase than the $\mathrm{H} 1$ sample, and the peak of the $\mathrm{WC}$ phases in the L2 sample becomes sharper than that of the $\mathrm{H} 1$ sample. This is because the $\mathrm{WC} / \mathrm{Co}$ deposits are completely melted near surface by laser irradiation, which is clear from the SEM image shown in Fig. 5.

Thus, the decarburization in L2 after laser melting is less extensive because numerous undissolved WC particles are well distributed, whereas the H1 coating is more easily decarburized due to the existence of numerous pores, un-melted powders, and oxide inclusions closer to the surface.

In the L2 sample, because a greater quantity of undissolved WC particles are well distributed and provide a better bonding with the matrix by forming the 


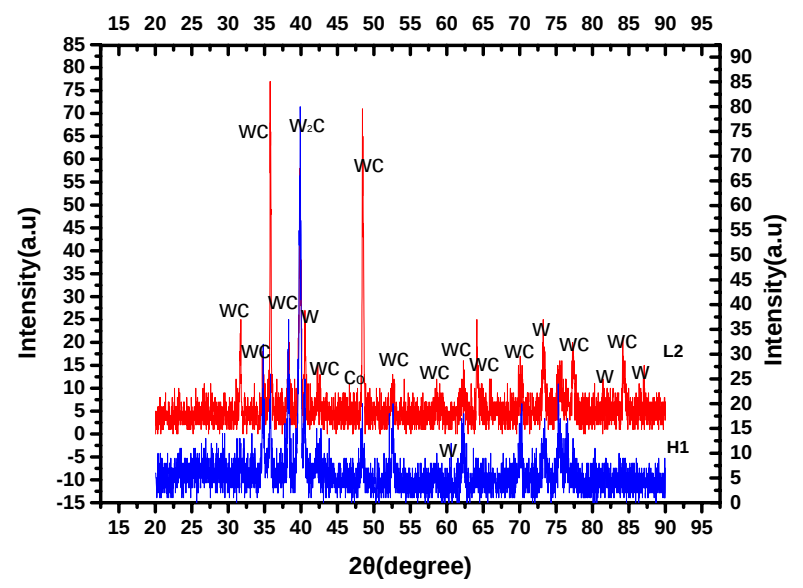

Fig. 8. XRD patterns of WC-8Co coatings produced by HVOF process (H1) and produced by the laser melting of the HVOF coating (L2).

carbides through diffusion-solution reaction, the laser treated HVOF-sprayed WC/Co composite coatings have the best wear resistance.

Figure 9 compares the wear volume of the coatings before and after laser irradiation. The wear volumes for HVOF (H1) and laser-treated HVOF-sprayed coatings $(\mathrm{L} 1, \mathrm{~L} 2)$ were $4.46 \times 10^{-2} \mathrm{~mm}^{3}, 9.17 \times 10^{-2} \mathrm{~mm}^{3}$ and $1.24 \times 10^{-2} \mathrm{~mm}^{3}$, respectively. Clearly, the largest wear volume of the coated specimens was almost one quarter of that of the uncoated substrate matrix. Among the coated samples, the wear volumes of the laser-treated HVOF sprayed WC-Co coatings are the lowest, indicating good wear resistance.

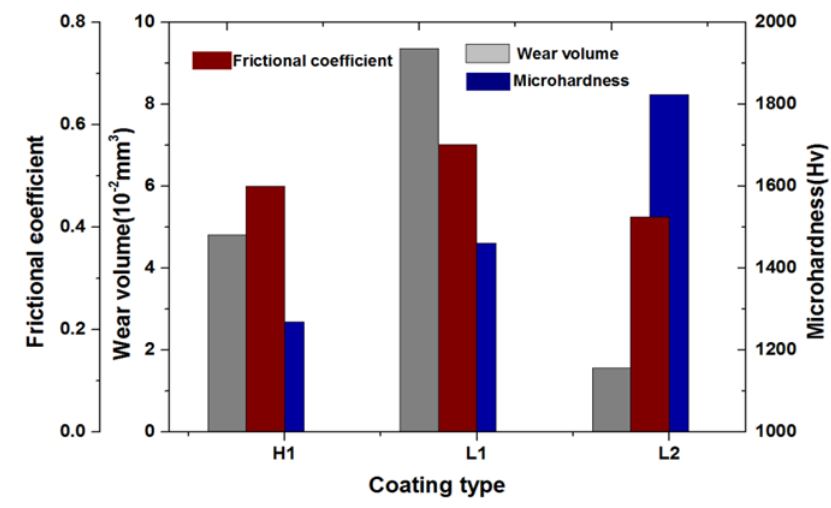

Fig. 9. Wear volume loss, frictional coefficient and microhardness of laser-melted HVOF sprayed coatings for two different cases(L1, L2) in comparison with those of HVOF sprayed coatings (H1).

On the other hand, a uniform hardness value of 1320 VHN was obtained for the H1 sample, and the hardness was significantly higher for L1 and L2 samples, having a value of $1480 \mathrm{VHN}$ and $1860 \mathrm{VHN}$, respectively. Microhardness and wear resistance of the L2 coating were much better than those of the H1 coating, and the best results were clear. As shown in Fig. 9, the friction coefficient at $0.48 \mu$ was slightly lower with lower wear volume losses for the L2 sample, and there is a slight increase in the coefficient of friction under similar conditions in the $\mathrm{H} 1$ sample.

In contrast, there is a coefficient of friction close to $0.67 \mu$ in the L1 sample. However, the friction coefficient is similar although the sprayed technique is different. The relationship between frictional coefficient and the wear volume is not obvious, and thus the information on frictional coefficient in this study could not help to improve wear resistance. As can be seen from the figure, there is minimal wear for the L2 sample, indicating that its wear resistance is best, and wear resistance of the $\mathrm{H} 1$ sample is the worst. This is closely related to the solidified carbide phases, phase constitutions, and wear behaviors in laser-melted HVOF-sprayed coatings.

On the other hand, by comparing the L2 sample with Fig. 6, it can be observed that the worn surface textures of the L1 sample are much looser than those of the L2 sample, which is probably due to the higher porosity and poor quality of surface coatings. In other words, the wear resistance of the coating is significantly enhanced when laser melting is performed at laser power of $1000 \mathrm{~W}$, and this wear resistance decreased when the laser power was reduced to $800 \mathrm{~W}$.

Overall, the L2 sample has three times lower wear volume value than the $\mathrm{H} 1$ sample. Thus, the comparison of the two spraying technologies shows that the laser-treated HVOF-sprayed WC/Co composite coatings give better results than the corresponding HVOF-sprayed coatings. This indicates that the laser-melted HVOFsprayed coating has excellent wear resistance.

\section{Conclusions}

This study shows that wear behaviors of the $\mathrm{WC} / \mathrm{Co}$ coatings deposited by HVOF can be improved by laser melting. The microstructural evolution and wear behaviors of the laser melted HVOF-sprayed coatings were characterized and compared with HVOF-sprayed coatings. The $\mathrm{WC} / \mathrm{Co}$ composite coating provides more undissolved material in case of laser-treated HVOFsprayed coating. The phase composition of the $\mathrm{WC} / \mathrm{Co}$ composite coating consists of $\mathrm{W}, \mathrm{C}, \mathrm{Co}$ and $\mathrm{O}$ elements, and there is a small peak of $\mathrm{W}_{2} \mathrm{C}$ type carbide. In addition, large peaks of tungsten-rich carbide WC in the coatings were observed by XRD. Worn surface microstructural observation comparing the HVOF-sprayed coatings and laser-treated HVOF-sprayed coatings show that weak scraping and caulking tracks with HVOF-sprayed coatings are visible in most contact regions, whereas slightly scuffed and worn tracks are found in the lasertreated HVOF-sprayed coatings. This result indicates that textures of the zirconium oxide area of the worn surface appear to be highly non isotropic during sliding wear, which leads to a remarkable increase in wearresistant properties. 
Furthermore, microhardness and wear resistance of WC/Co composite coating prepared by laser-treated HVOF-sprayed coating are much higher than those of HVOF-sprayed coatings, and the best wear resistance of the WC/Co composite coating is obtained by laser irradiation. Overall, this study finds that the laser-based HVOF-sprayed coated surface with WC/Co composite coatings fabricated on 45 carbon substrate by HVOF were better when prepared using laser treatment technology.

\section{Acknowledgments}

This research has been financed by the Natural Science Foundation of Fujian Province (Project Numbers: 2015J01181 and 2015J01629). It has also been supported by the Public Service Platform for Technical Innovation of Machine Tool Industry in Fujian Province.

\section{References}

[1] J. Pereira, J. Zambrano, M. Licausi, M. Tobar, V. Amigo Wear 330-331, 280 (2015).

[2] D. Bartkowski, A. Młynarczak, A. Piasecki, D. Bartłomiej, M. Gościański, A. Bartkowska, Opt. Laser Technol. 68, 191 (2015).

[3] M. Afzal, M. Ajmal, A. Nusair Khan, A. Hussain, R. Akhter Opt. Laser Technol. 56, 202 (2014).

[4] J. Nurminen, J. Näkki, P. Vuoristo, Int. Conf. Sci. Hard. Mater. 27(2), 472 (2009).

[5] S. Zhou, X. Dai, H. Zheng, Opt. Laser Technol. 44, 190 (2012).

[6] F. Weng, H.J. Yu, C.Z. Chen, J.L. Liu, L.J Zhao, Journal of Alloys and Compounds 650, 178 (2015).

[7] T.Y. Cho, J.H. Yoon, K.S. Kim, K.O. Song, Y.K. Joo, W Fang, Adv. Mater. Res. 26-28, 1325 (2007).

[8] V. Rajinikanth, K Venkateswarlu, Tribology International 44, 1711 (2011).
[9] P.H. Shipway, D.G. McCartney, T. Sudaprasert Wear 259, 820 (2005).

[10] B.V. Krishna, V.N. Misra, P.S. Mukherjee, P. Sharma, Int. Journal of Refractory Metals and Hard Materials 20, 355 (2002).

[11] J.M. Guilemany, S. Dosta, J.R. Miguel, Surface and Coatings Technology 201, 1180 (2006).

[12] J. Kawakita, S. Kuroda, T. Kodama, Surface and Coatings Technology 166, 17 (2003).

[13] A. García, M. Cadenas, M.R. Fernández, A. Noriega, Wear 305, 1 (2013).

[14] A.S. Khanna, S. Kumari, S. Kanungo, A. Gasser, Int. Journal of Refractory Metals and Hard Materials 27, 485 (2009).

[15] H.S. Ni, X.H. Liu, X.C. Chang, W.L. Hou, W. Liu, J.Q. Wang, Journal of Alloys and Compounds 467, 163 (2009).

[16] C.P. Paul, H. Alemohammad, E. Toyserkani, A. Khajepour, S. Corbin, Mater. Sci. Eng. A 464, 170 (2007).

[17] Y. Xiong, J.E. Smugeresky, J.M. Schoenung, Journal of Materials Processing Technology 209(10), 4935 (2009).

[18] Y. Yang, H.C. Man, Surface and Coatings Technology 132, 130 (2000).

[19] K. Wang, J. Liu, D. Han, Surface Engineering 12(3), 235 (1996).

[20] Z.Y. Taha-al, M.S. Hashmi, B.S. Yilbas, Journal of Materials Processing Technology 209, 3172 (2009).

[21] D. Aleksendric, C. Duboka, Wear 261, 269 (2006).

[22] M.D. Jean, C.D. Liu, J.T. Wang, Applied Surface Science 245, 290 (2005).

[23] M.D. Jean, B.T. Lin, J.H. Chou, Surface and Coatings Technology 201, 3129 (2006).

[24] M.D. Jean, B.T. Lin, J.H. Chou, Acta Materialia 55, 1985 (2007). 